\title{
THE PATTERN OF PROTON MAGNETIC RESONANCE SPEC- TROSCOPY IN NON-NEOPLASTIC ENCEPHALIC LESIONS
}

\author{
Andréia V. Faria' ${ }^{1}$, Fabiano Reis ${ }^{1}$, Verônica A. Zanardi ${ }^{1}$, José R. Menezes ${ }^{1}$, Fernando Cendes $^{2}$ \\ ABSTRACT - The purpose of this article is show the role of proton magnetic resonance spectroscopy (MRS), associated with mag- \\ netic resonance images, in the study of non-neoplastic disorders, helping in diagnosis and better characterization of the nature of \\ the lesion. Herein, we analyzed single voxel proton spectroscopy in eight different non-neoplastic lesions, displayed in six cate- \\ gories (infectious, ischaemic, demyelinating, inflammatory, malformation of development and phacomatosis). The presence or the \\ ratios of signal intensities brain tissue metabolites observed with this technique ( $N$-acetyl aspartate, choline, creatine, lactate and \\ lipids) helped in their differentiation with neoplastic lesions and helped in correct diagnosis. In infectious diseases, signals of acetate, \\ succinate and aminoacids were also important. In conclusion, proton MRS is a noninvasive method, very useful as an additional \\ technique to define the nature of non-neoplastic encephalic lesions.
}

KEY WORDS: spectroscopy, magnetic resonance, non-neoplastic encephalic lesions.

\begin{abstract}
Padrão da espectroscopia do hidrogênio por ressonância magnética nas lesões encefálicas não neoplásicas
RESUMO - 0 propósito deste artigo é mostrar o valor da espectroscopia de hidrogênio associada a imagens de ressonância magnética (RM), no estudo de lesões encefálicas não neoplásicas, ajudando no diagnostico e na melhor caracterização de grupos etiológicos. Analisamos espectroscopias de hidrogênio com voxel único em oito diferentes doenças não neoplásicas, divididas em seis categorias (infecciosas, isquêmicas, desmielinizates, inflamatórias, malformações do desenvolvimento cortical e facomatoses). A presença e as relações entre a intensidade do sinal dos metabólitos do tecido nervoso observados com esta técnica ( $\mathrm{N}$-acetil aspartato, colina, creatina, lactato e lipídios) ajudaram na diferenciação de lesões neoplásicas e permitiram o diagnostico correto. Nas doenças infecciosas, os sinais do acetato, succinato e aminoácidos também foram importantes. Concluímos que a espectroscopia do hidrogênio por RM é um método não invasivo muito útil como técnica adicional para definir a natureza não neoplásica de lesões encefálicas.
\end{abstract}

PALAVRAS-CHAVE: espectroscopia, ressonância magnética , lesões encefálicas não neoplásicas.

Following the widespread recognition of magnetic resonance (MR) as a diagnostic method of central nervous system (CNS) pathologies, it was envisaged that it would be possible to have a differential diagnosis made solely through image analysis, considering the vast etiologic groups. However, because MR images are based on water signal and, in consequence, reflect the tissue hydration degree, MR appearance of such distinct pathologies as tumor or ischaemia can be very similar. It is in this context that proton magnetic resonance spectroscopy (M RS) arises as an auxiliary method that may help to identify the nature of some encephalic lesions ${ }^{1,2}$.

Proton M RS provides a non-invasive method for examining a wide variety of metabolites in the human brain, includ- ing $\mathrm{N}$-acetylaspartate (NAA), a compound present only in neurons; choline-containing compounds (Cho), which participate in membrane synthesis and degradation; phosphocreatine and creatine (Cre), which play a major role in energy metabolism; lactate (lac), a resultant of increased anaerobic glycolysis; lipids, correlated with necrosis ${ }^{3}$ and other such as succinate, aminoacids, glycine, glutamine and inositol. The acquisition of the spatially localized metabolic information available from proton spectra can be correlated with $M R$ images and other imaging methods and may lead development of a set of physiological, anatomical and biochemical indices which may provide a powerful approach for investigating the underlying basis for many clinical disorders.

1Department of Radiology and 2Neurology, State University of Campinas - (UNICAM P), Campinas SP, Brazil.

Received 14 September 2003, received in final form 19 December 2003. Accepted 20 January 2004.

Dr. Fernando Cendes - Departamento Neurologia, Faculdade de Ciências Médicas - UNICAMP. Caixa Postal 6111 - $13083-970$ Campinas SP - Brasil. E-mail: fcendes@unicamp.br 
A list of pathological conditions that have been documented by proton MRS includes brain tumor, stroke, demyelinating diseases, metabolic disorders, dementia and partial epilepsies. Additional single voxel proton MRS for distinguishing neoplastic from non-neoplastic encephalic lesions raises accuracy up to $96 \%{ }^{4}$. The purpose of this study is to present proton MRS pattern of non-neoplastic brain lesions that may help in their differentiation from tumors and have the potential for avoiding invasive diagnostic procedures.

\section{METHOD}

We selected eight proton M RS that were helpful in the differentiation of neoplastic lesions from other etiologies. All exams were performed at our MR service in the University of Campinas - UNICAM P.

T1-weighted spin echo sagittal images $\left(6 \mathrm{~mm}\right.$ slice, $180^{\circ}$ flip angle, TR (relaxation time) / TE (echo time) $=550 / 10,200 \times 350$ matrix, $25 \times 25 \mathrm{~cm}$ field of vision - FOV) were used for planing the other acquisitions. The basic M RI protocol was axial T1-weighted spin echo images $(\mathrm{TR} / \mathrm{TE}=540 / 12)$, T2-weighted double spin echo (TR/TE = $4800 / 128-16)$ and fluid attenuation inversion recovery (FLAIR), (TR/TI inversion time) $/ \mathrm{TE}=10099 / 2550 / 90)$. Coronal and sagittal SE T1weighted images after gadolinium administration were performed when indicated. We also acquired diffusion weighted images (TR/TE $=500 / 107.542$ ).

Single voxel proton MRS was acquired using PRESS sequence $(\mathrm{TR} / \mathrm{TE}=1500 / 135 \mathrm{~ms}$, number of excitation (NEX =200). After scout anatomical images in axial planes for localization of the lesion, one single voxel $\left(8 \mathrm{~cm}^{3}\right)$ was placed over the center of the lesion. Prior to the acquisition, a localized shimming at the region of interest (ROI) was performed, followed by water suppression adjustment. Localized shimming was repeated two or three times, if necessary, to ensure a good field homogeneity and until the ${ }^{1} \mathrm{H}$ signal from water within the ROI became as narrow as possible.

Spectra were post-processed using software supplied by the machine manufacturer (Elscint Prestige 2T, Haifa, Israel). After zerofilling and baseline correction, we determined peak areas by integration of the corresponding signals from $\mathrm{N}$-acetyl compounds (NAA) at 2.01 parts per million (ppm), choline-base compounds (Cho) at 3.2 ppm, Creatine and phosphocreatine contained compounds (Cre) at $3.0 \mathrm{ppm}$ and lactate (lac) at $1.3 \mathrm{ppm}$. Other compounds such as lipids, succinate and aminoacids were studied in specific cases.
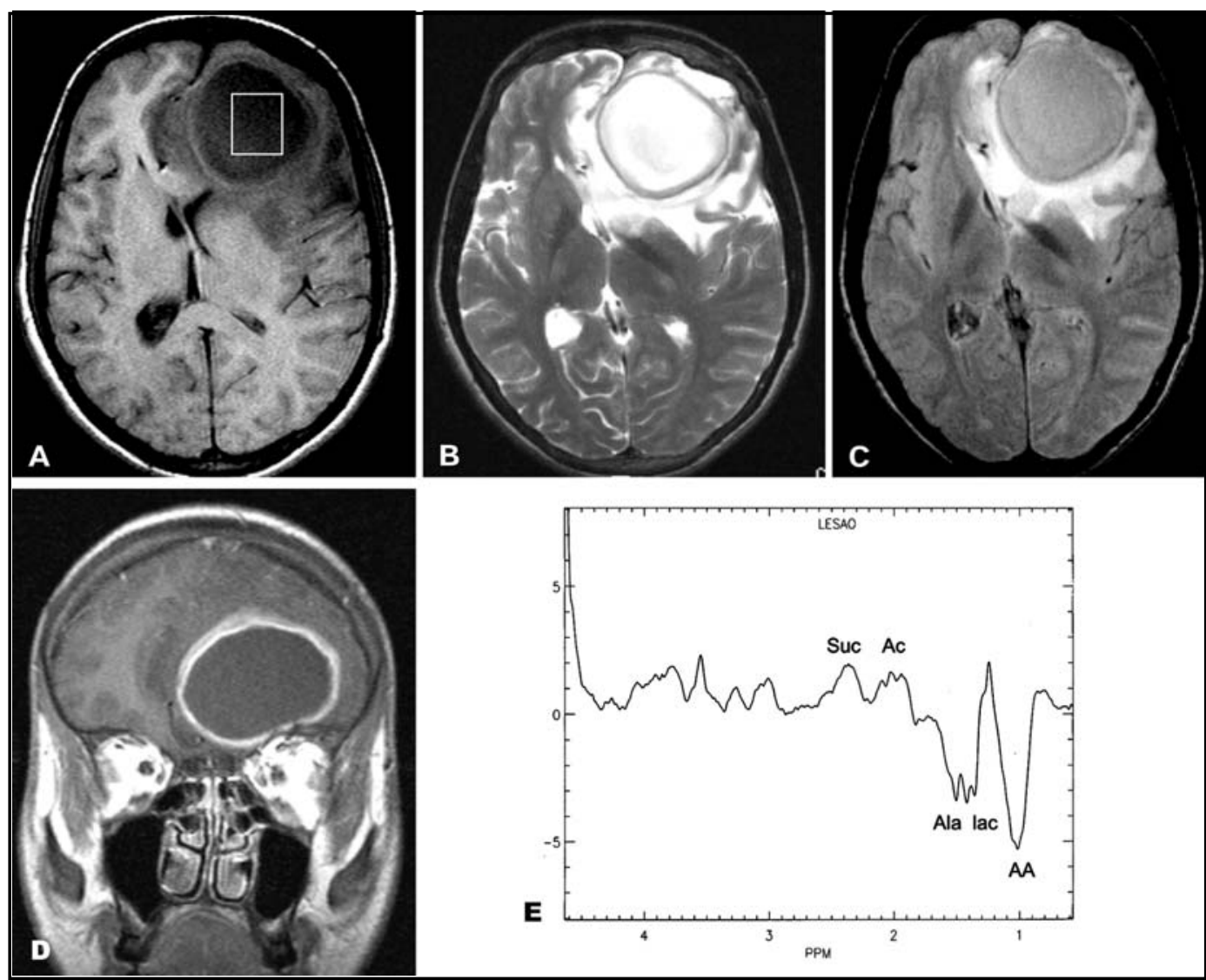

Fig 1. Bacterial abscess. Large frontal rounded lesion, intensely hydrated, with an extensive surrounding edema with mass effect in $T 1$ (a), T2 (b) and FLAIR (c) weighted images with a ring-like gadolinium enhancement (d). Proton MRS (e), shows decrease of NAA, choline(Cho) and creatine (Cre) signals and presence of succinate (suc) and acetate (ac) signals (at 1.9-2.5 ppm); and alanine (ala) and lactate (lac) signals (at 1.3-1.5 ppm). The aminoacid multiplet (AA) at 0.9 ppm is inverted in acquisitions with TE of $135 \mathrm{~ms}$, which makes easy to differentiate from lipids signal. 

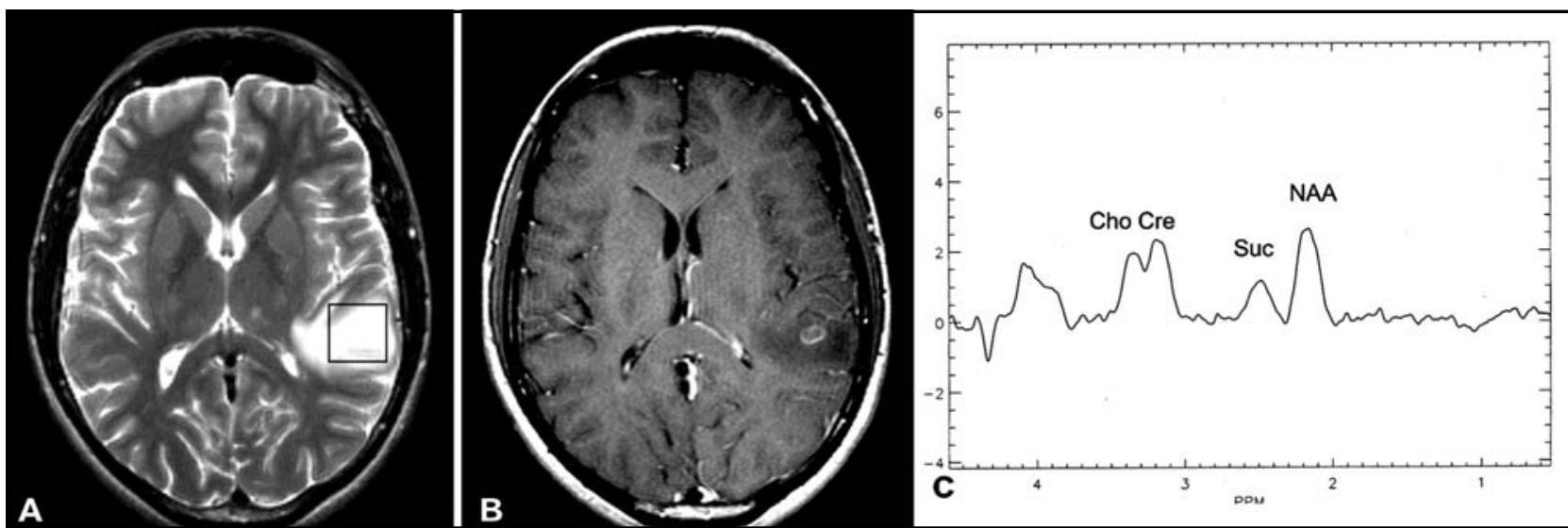

Fig 2. Neurocysticercosis. Subcortical lesion in left parietal region, surrounded by edema - hyperintense signal in T2- weighted image (a) - with a ring-like contrast enhancement (b). MRS (c), shows increased succinate signal at $2.4 \mathrm{ppm}$. NAA is present, probably because partial volume effect from surrounding tissue. Broad peaks and poor separation of choline (Cho) and creatine (Cre) peaks are due to proximity to skull.

\section{RESULTS}

Figures 1 to 8 summarizes the imaging and proton MRS findings in the eight patients included in this report.

Patient 1 (Fig 1) a 15 years old male patient, with headache and alteration in behavior that began 5 days before. He had a previous head trauma and subsequent cerebropinal fluid (CSF) fistula that regressed spontaneously. Computerized tomography (CT) and MR showed a left hydrated frontal lesion with ring-like contrast enhancement and extensive surrounding edema. A necrotic tumor could be a differential diagnosis. MRS confirmed the hypothesis of abscess due to the presence of aminoacid peak and elevated succinate signal intensity. The lesion was surgically aspirated and culture revealed infection by Pneumococcus sp.

Patient 2 (Fig 2) a 21 years old male patient, evaluated after his first episode of generalized tonic-clonic seizure. CT and RM showed solitary lesion with ring-like contrast enhancement and extensive surrounding edema. M RS showed elevated succinate levels and relative maintenance of other metabolites corroborating the hypothesis of neurocysticercosis. CSF analysis showed pleocytosis and positive imunology for neurocysticercosis. There was total regression of the lesion after treatment with albendazol.

Patient 3 (Fig 3) a 41 years old female patient with loss of consciousness and right hemiplegia. CT and MRI showed a large lesion in left hemisphere with bleeding points. MRS corroborated clinical and imaging hypothesis of subacute ischaemia due to lac peak and increased cho.

Patient 4 (Fig 4) a 22 years old female patient with paresthesia that began two weeks before. Neurological examination revealed left hemiparesis and hypoesthesia. RM showed a large expansive lesion in right hemisphere, with mass effect. Although neoplasm was the first hypothesis by imaging, rel- ative maintenance of NAA peak was unusual if considering tumor. Sterotaxic biopsy showed gliosis and other non-specific inflammatory abnormalities. Clinical evolution, marked by relapses characterized by as aphasia, ataxia and psychomotor slowing, and examination of the CSF confirmed the diagnosis of multiple sclerosis.

Patient 5 (Fig 5) a 5 years old girl, with macrocephaly with subtle and progressive regression in neurological development since 1 year. Brother with the same features. M R images revealed a diffuse white matter disease. MRS showed total tissue destruction with absence of all metabolites, helping in diagnosis of vanishing white matter disease. Although MR imaging in this patient is characteristic of white matter disease, the M RS pattern described here could help in other patients and in the follow up.

Patient 6 (Fig 6) a 19 years old female patient with medical resistant epilepsy. M R images show ed a mass with the same characteristics of gray matter. Although this pattern is characteristic of subcortical heterotopia, the normal M RS pattern illustrated here could help in other patients with less conspicuous heterotopia.

Patient 7 (Fig 7) a 10 years old male patient with type 1 nerofibromatosis: neurofibromata, cafe-au-lait macules and sphenoid dysplasia at CT. RM imaging for tumor screening showed bilateral thalamic lesion. M RS makes the hypothesis of neoplasm less likely because of the maintenance of NAA peak and the discrete Cho increase. The diagnosis of transitory basal nucleus lesions of neurofibromatosis was confirmed in follow up.

Patient 8 (Fig 8) a 17 years old male patient. Epilepsia partialis continua involving left hand and arm since 6 years old with slowly progressive left hemiplegy. Clinical data and discrete hemispheric asymmetry in CT and M R images indicated Rasmussens encephalitis. MRS supported this hypothesis 

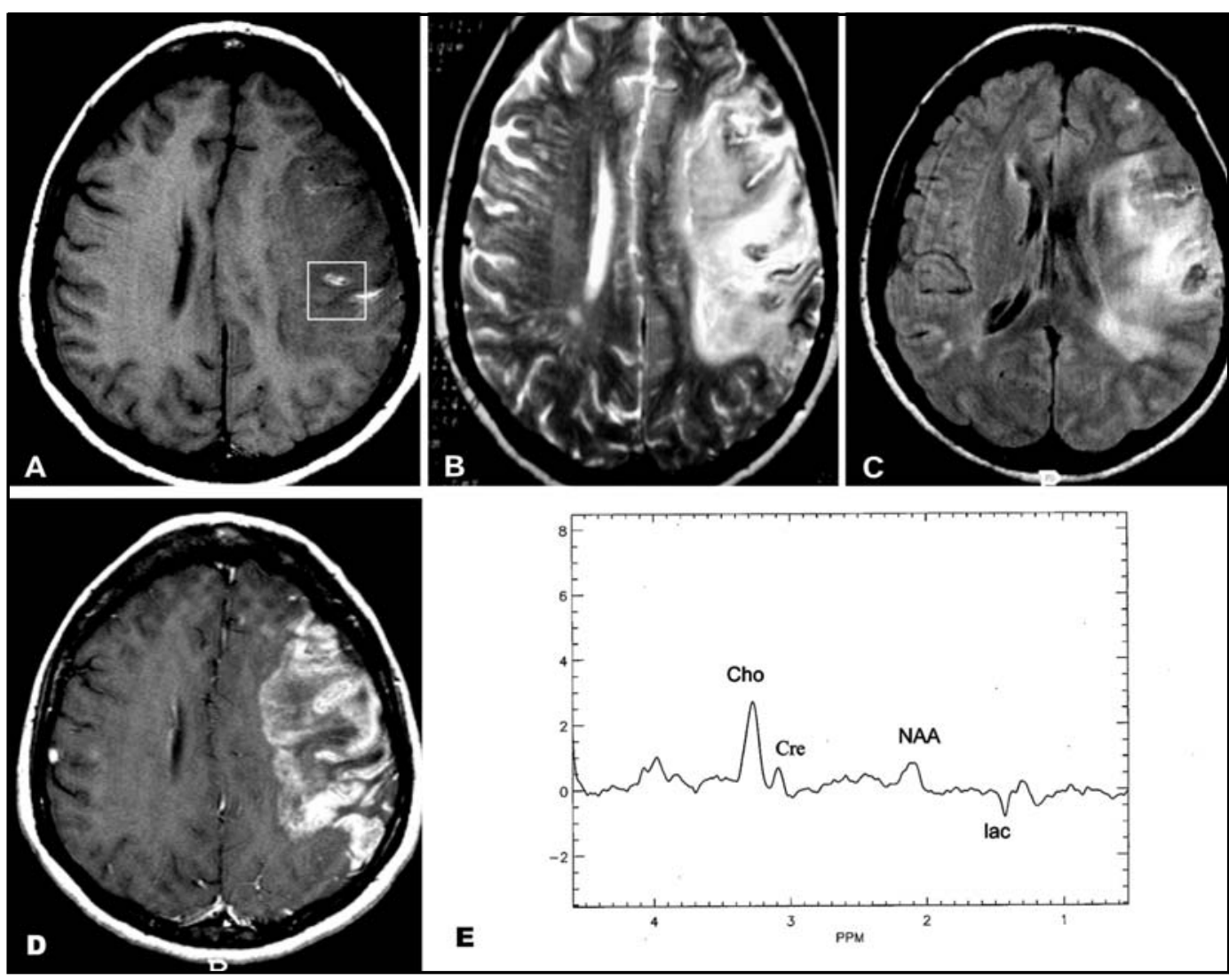

Fig 3. Subacute infarction. In the left parietal region of a patient with subtle right hemiparesis, an extensive area, with ill delimited borders and mass effect, hypointense in T1-weighted images with hyperintense focus corresponding to meta-hemoglobin, due to subacute bleeding (a) and hyperintense in T2 (b) and FLAIR (c) weighted images. There is a pronounced gadolinium enhancement (d). At MRS (e), decreased NAA and creatine (Cre) signals and increased choline (Cho) and presence of lactate (lac).

showing distinct pattern between hemispheres with reduced NAA, discrete increase of Cho and increased lac in affected hemisphere.

\section{DISCUSSION}

Acetate, succinate and aminoacid multiplet - composed of valine, leucine and isoleucine - are markers of bacterial abscess $^{5}$ (Fig 1) and they are not detected in necrotic tumors, such as metastasis and glioblastoma, which sometimes mimic brain abscess in conventional MR. Other type of abscess, such as tuberculous, do not show this pattern ${ }^{6}$. In addition, the characteristic neural tissue peaks (NAA, Cho, Cre) are absent or decreased, confirming the brain tissue destruction in necrotic area.

Neurocysticercosis (Fig 2) is the most common parasitic CNS infection across the world 7 . When the acute lesion is single, parenchymatous, with reactive edema, it may simulate an encephalic tumor. However, succinate signal is elevated in neurocysticercosis and have been associated with the aerobic metabolism of scolices ${ }^{8}$. Aminoacid peaks have also been found in neurocysticercosis lesions ${ }^{8}$.

Subacute infarction (Fig 3) associated with edema, mass effect and blood -brain barrier rupture is commonly confused with tumors. Lactate increase can be detected minutes after the ischaemia and continues increasing in the following hours. This pattern contributes to diagnosis and does not necessarily represent an irreversible process. Choline might be elevated in acute infarcts because the high cellular turn-over. Changes in Cre signal intensity are variable ${ }^{9}$. Subacute infarctions show decreased NAA (as a response to neuronal loss and dysfunction) and increased lac, with progressive Cho reduction in the chronic phase. How ever, this last feature has a variable character?.

The acute multiple sclerosis (Fig 4) plaques may produce large mass effect with surrounding edema and blood-brain barrier rupture (pseudotumoral multiple sclerosis lesions), at times simulating neoplasm, in particular when there is only one lesion. In proton MRS they are characterized by lac increase, depending on the degree of inflammatory reaction, and by increased Cho/Cre ratios due to acute myelin break down, but usually not so intense as in neoplastic lesions ${ }^{10}$. Chronic 

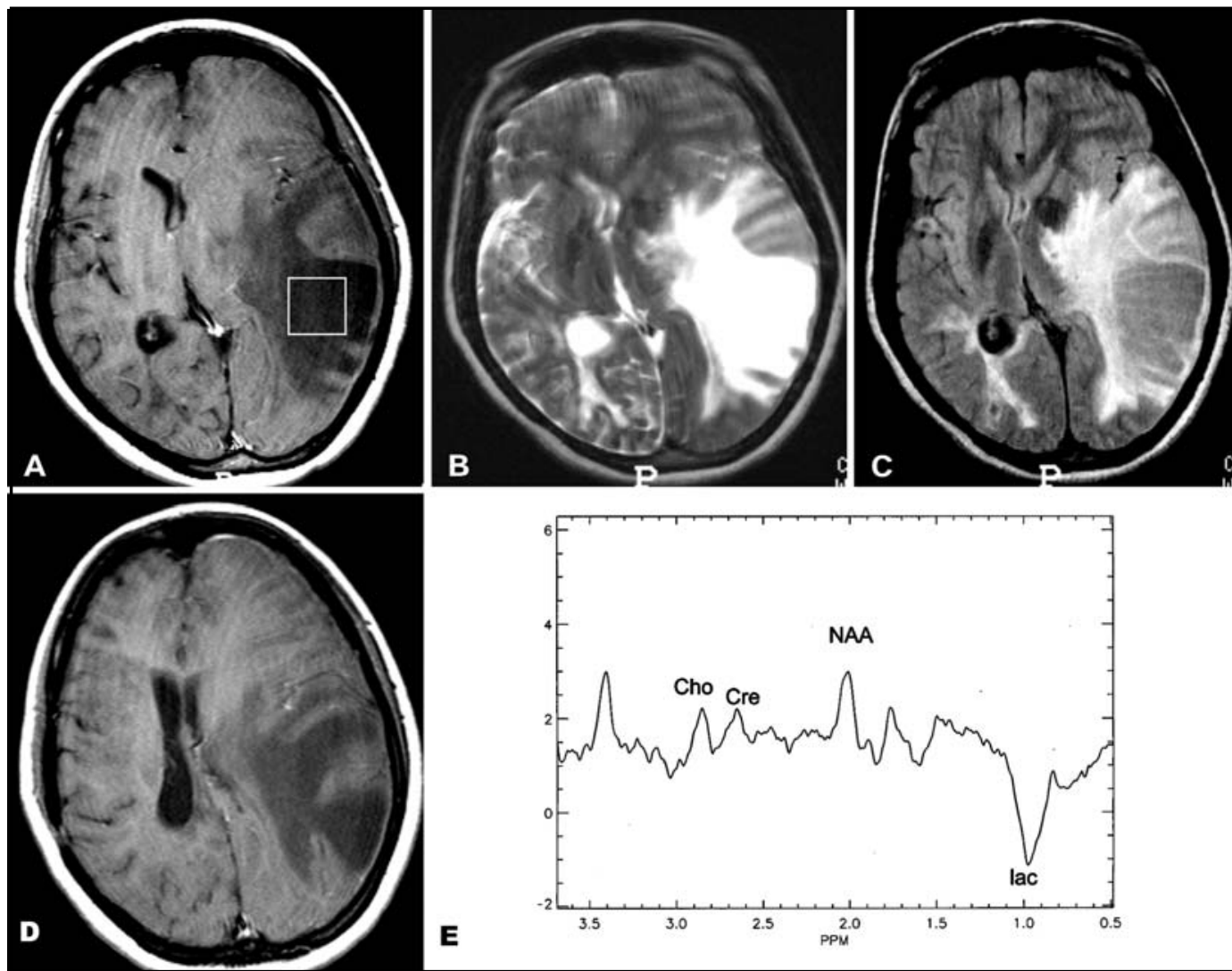

Fig 4. Multiple sclerosis. Centered in corona radiata, an extensive, infiltrate lesion, with large mass effect, hypointense in T1 weighted images (a) and hyperintense in T2 (b) and FLAIR (c), with slight and sparse areas of contrast enhancement (d). Decreased NAA signal and increase in lactate (lac) are observed (e).
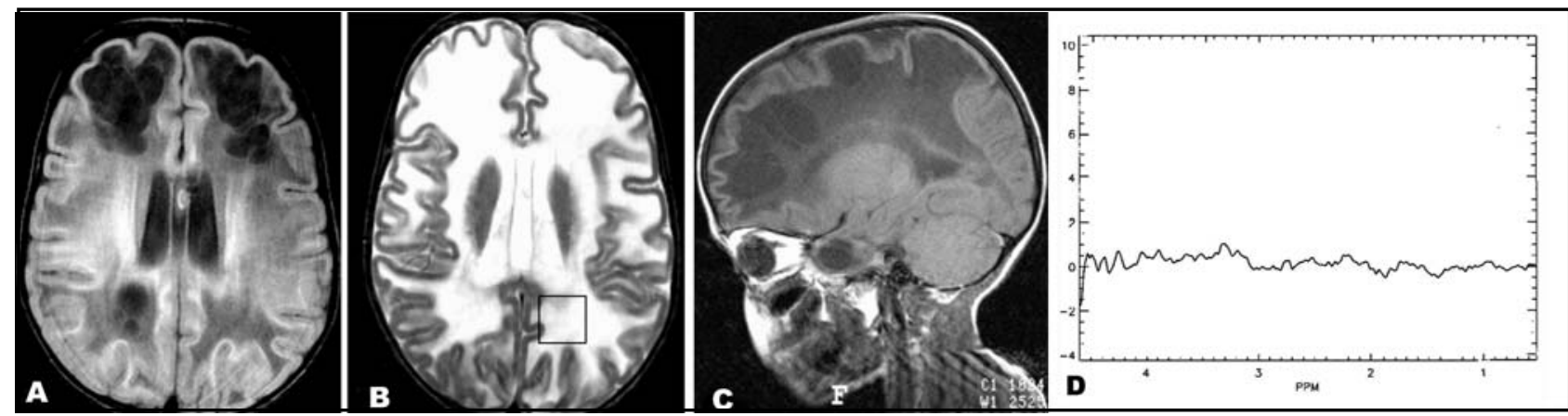

Fig 5. Vanishing white matter disease. Obvious abnormal MR signal in white matter, hypointense in T1 (a) and hyperintense in T2 weighted images (b) which corresponds to demyelinization. In FLAIR images (c), hypointense signal areas correspond to lacunes. Marked decrease or absence of all brain metabolites in $M R S(d)$.

plaques present reduced NAA/Cre ratios in the center of the lesion, as consequence of irreversible axonal injury and partial or complete recover of NAA signal in the periphery of the lesion ${ }^{11}$. Therefore, a single M RS exam in acute multiple sclerosis lesions may show a very similar pattern as seen in brain tumors. However, follow up M RS exams will show distinct patterns of metabolic changes in these two conditions.
Demyelinating diseases in children show a non specific MR imaging pattern, particularly when there are lesions with ill defined borders with hyperintense signal in long TR sequences, or when there is a rupture of blood-brain barrier, with contrast enhancement ${ }^{12}$. Proton MRS, although non specific within this large group of pathologies, may be helpful for the study of the disorder evolution ${ }^{13}$. Canavan disease is an example of how promising is proton MRS for investigation of metabolic disor- 

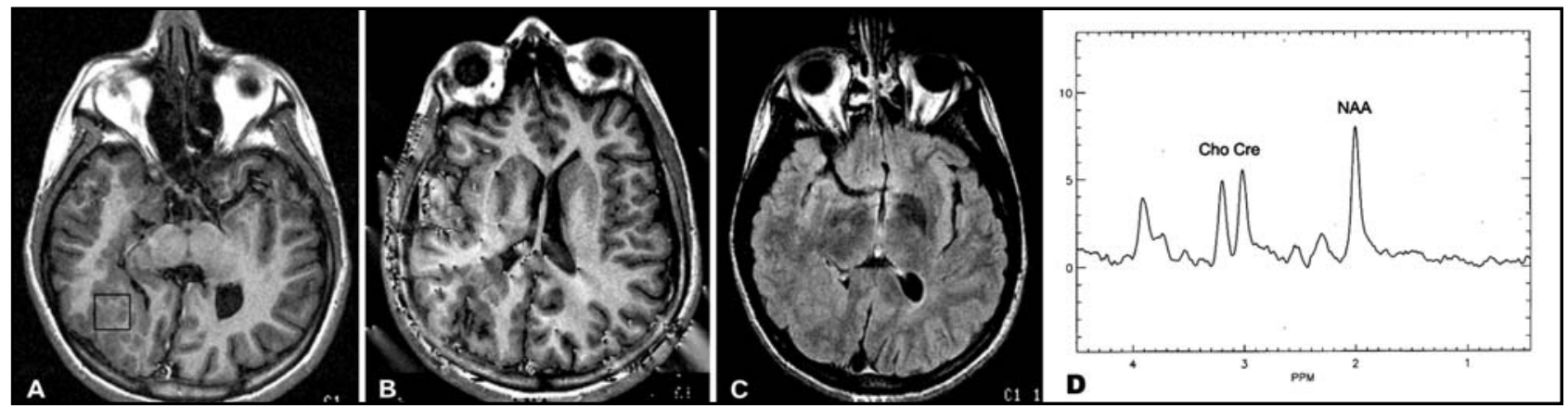

Fig 6. Heterotopia. Heterogeneous mass with the same signal of gray matter in $\mathrm{Tl}(a, b)$ and FLAIR (c) weighted images, in the right parietal regions, with an apparent mass effect deriving from deformation of the posterior horn of the right lateral ventricle. The proton MRS pattern is similar to that of the normal brain tissue $(d)$.
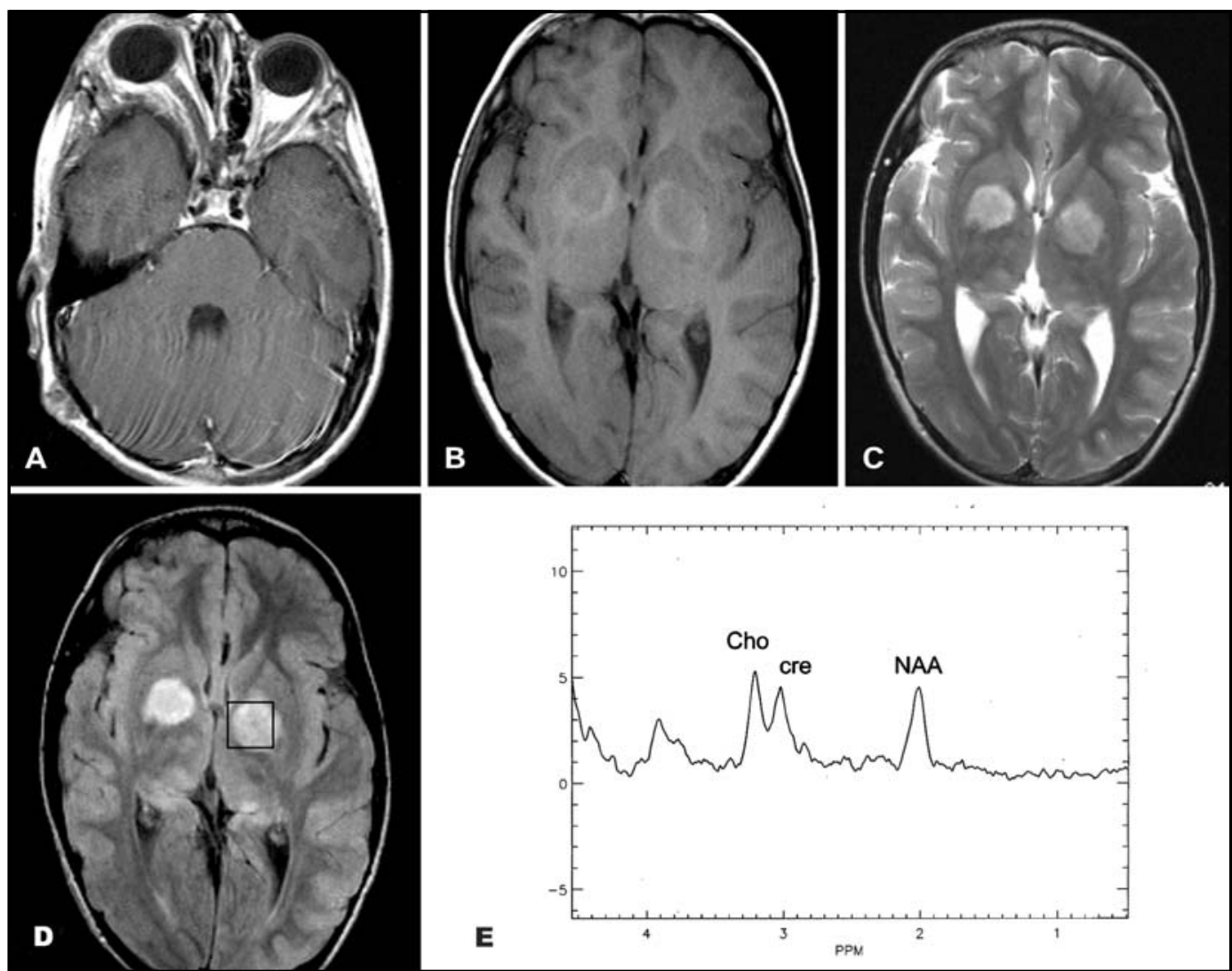

Fig 7. Type 1 neurofibromatosis and typical hypoplasic sphenoid wing (a). Basal nucleus described in this disease presents hypointense signal in $T 1$ weighted images (without contrast) with a thin hyperintense peripheral ring (b), and hyperintense signal in T2 (c) and FLAIR weighted images (d). At proton MRS (e) increased Cho/NAA ratio because a relative increase of choline (Cho) and a moderate decrease in NAA.

ders. The marked increase in NAA as a result of deficiency of the aspartocyclase enzyme, necessary for the break down of NAA, is a pathognomonic finding'. In opposite, other demyelinating diseases, mainly in advanced phases, show low NAA levels and progressive decrease of signal intensity of all metabolite signals, as in vanishing white matter disease (Fig 5).
Heterotopias (Fig 6) may be clinically manifested as epilepsy and, in MR images, as large masses, sometimes simulating tumors. However, proton M RS show normal peak areas or discrete relative NAA reduction ${ }^{14}$.

In neurofibromatosis (Fig 7), proton M RS assists in the differentiation of transitory white matter lesions from astrocytomas, both associated with this phacomatosis. Although in 


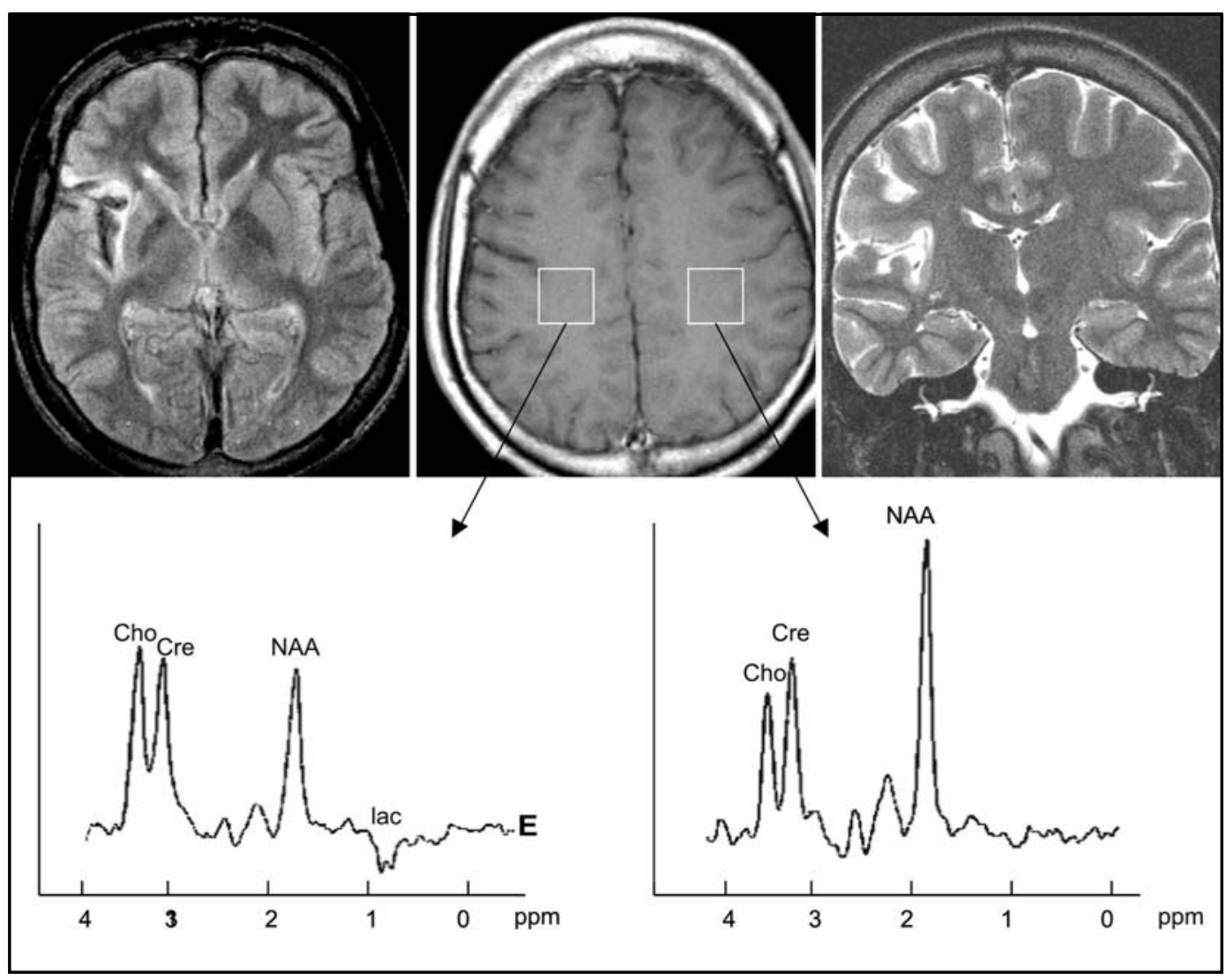

Fig 8. Rasmussen's encephalitis. Right insular hyperintense signal in axial FLAIR (top, left) and coronal T2 (top, right) weighted images with parenchyma retraction, noted by cortical sulci asymmetry. Decreased NAA signal and increased choline (Cho) and lactate (lac) are observed relative to contralateral homologous area (bottom).

both situations these is a decrease in the NAA/Cre ratio and a significant increase in the Cho/Cre ratio, Cho increase is discrete and infrequent in the transitory white matter lesions ${ }^{15,16}$.

The gliotic areas of Rasmussen's encephalitis (Fig 8), with hyperintense 2 signal, may be confused with infiltrate process when hemispheric atrophy is not so pronounced. Proton MRS, however, shows a decrease in the NAA/Cre ratio, indicating the secondary neuronal loss observed in this instance. Lactate accumulation is associated with the repetitive neuronal epileptic activity in this disorder ${ }^{17,18}$.

\section{CONCLUSION}

Proton M RS contributed to correct diagnosis in encephalic lesions of diverse etiologies, such as infectious, ischaemic, demyelinating, inflammatory, malformation of brain development and phacomatsis. In infectious disease, the presence of aminoacid multiplet and acetate, succinate supported the diagnosis. Other categories were differentiated by the pattern of ratios among NAA, Cre, Cho and lac in conjunction with other imaging findings.

In conclusion, proton MRS is a noninvasive method, very useful as an additional technique to define the nature of nonneoplastic encephalic lesions. Together with image analysis, it may be the key to etiologic diagnosis or, at least, definition of the group where the lesion is classified (inflammatory, infectious, demyelinating, ischaemic, dysplastic or gliotic).

\section{REFERENCES}

1. Petroff OA, Pleban LA, Spencer DD. Symbiosis between in vivo and in vitro NMR spectroscopy: the creatine, $\mathrm{N}$-acetylaspartate, glutamate, and GABA content of the epileptic human brain. Magnetic Resonance Imaging 1995;13:1197-1211.

2. Lenkinski RE, Schmal MD. MR spectroscopy and the biochemical basis of neurological disease. In Atlas SW (ed). Magnetic resonance imaging of the brain and spine. New York: Raven, 1991:1099.

3. Gill SS, Thomas DGT, VanBrugen N, et al. Proton spectroscopy of intracranial tumors: in vivo and in vitro studies. J Comp Assist Tom 1990;14:497-504.

4. Rand SD, Prost R, Haughton V, et al. Accuracy of single-voxel proton MR spectroscopy in distinguishing neoplastic from non-neoplastic encephalic lesion. Am J Neuroradiol 1997;18:1965-1704.

5. Grand S, Passaro G, Ziegler A, et al. Necrotic tumor versus brain abscess: importance of amino acids detected at ${ }^{1} \mathrm{H}$ MR spectroscopy: initial results. Radiology 1992;213:785-793.

6. Grupta RK, Vatsal DK, Chawla S, et al. Differentiation of tuberculous from pyogenic brain abscess with in vivo proton spectroscopy and magnetization transfer MR imaging. Am J Neuroradiol 2001;22:1503 - 1509.

7. Garcia HH, Gonzalez AE, Evans CA, Gilman RH. Taenia solium cysticercosis. Lancet 2003;16:547-556

8. Pandit S, Lin A, Gahbauner H, Libertin CR, Erdogan B. MR spectroscopy in neurocysticercosis. J Comp Assist Tom 2001;25:950 - 952. 
9. Maheshwari SR, Fatterpekar GM, Castillo M, Mukherji SK. Proton MR spectroscopy of the brain. Seminars in Ultrasound, CT and MRI 2000;21:434-451.

10. De Stefano N, Narayanan S, Matthews PM, Francis GS, Antel JP, Arnold DL. In vivo evidence for axonal dysfunction remote from focal cerebral demyelination of the type seen in multiple sclerosis. Brain 1999;122:1933-1939.

11. Simone IL, Federico F, Trojano M, et al. High resolution proton spectroscopy of cerebrospinal fluid in MS patients: comparison with biochemical changes in demyelinating plaques. J Neurol Sci 1996;144:182 - 190.

12. Tzika AA, Ball WS, Vigneron DB, Dunn RS, Nelson SJ, Kirks DR. Clinical proton MR spectroscopy of neurodegenerative disease in childhood. Am J Neuroradiol 1993;14:1267-1281.

13. Castillo M, Kwock L, Mukherji SK. Clinical applications of proton MR spectroscopy. Amer J Neuroradiol 1996;17:1-15.

14. Li LM, Cendes F, Bastos AC, Andermann F, Dubeau F, Arnold DL. Neuronal metabolic dysfunction in patients with cortical developmental malformations: a proton magnetic resonance spectroscopic imaging study. Neurology 1998;50:755-759.

15. Jones AP, Gunawardena WJ, Coutinho CMA. ${ }^{1} \mathrm{H}$ MR spectroscopy evidence for the varied nature of asymptomatic focal brain lesions in neurofibromatosis type 1. Neuroradiology 2001;43:62 - 67 .

16. Wang PY, Kauffmann WE, Koht CW, Denckla MB, Barker PB. Thalamic involvement in neurofibromatosis type 1: evaluation with proton magnetic resonance spectroscopy imaging. Ann Neurol 2000;47:447 - 484.

17. Mattheus PM, Andermann F, Arnold DL. Proton magnetic resonance spectography study of chronic encephalitis and epilepsy. In Chronic encephalitis and epilepsy: Rasmussen's syndrome. Boston: ButterworthHeinemann, 1991:73-77.

18. Cendes F, Andermann F, Silver K, Arnold DL. Imaging of axonal damage in vivo in Rasmussen's syndrome. Brain 1995;118:753-758. 